Validation and intercomparison of two vertical-mixing schemes

V. Fernández et al.

\section{Validation and intercomparison of two vertical-mixing schemes in the Mediterranean Sea}

V. Fernández ${ }^{1}$, L. Umlauf ${ }^{2}$, S. Dobricic ${ }^{1}$, H. Burchard ${ }^{2}$, and N. Pinardi ${ }^{3}$

${ }^{1}$ Instituto Nazionale di Geofisica e Vulcanologia, Bologna, Italy

${ }^{2}$ Baltic Sea Research Institute, Warnemunde, Germany

${ }^{3}$ Corso di Science Ambientali, University of Bologna, Ravenna, Italy

Received: 20 September 2006 - Accepted: 13 October 2006 - Published: 8 November 2006

Correspondence to: V. Fernández (fernandez@ingv.it)
Title Page
Abstract

Conclusions

Tables

14

$+$

Back 


\section{Abstract}

In this study, two types of vertical turbulence closure models are tested in the Mediterranean Sea in a one-dimensional configuration. The numerical experiments are performed at different locations in the Mediterranean for which the year 2004 is simulated.

5 The model results are then compared and validated with in-situ temperature observations. For the model simulations, initial profiles of temperature and salinity come from the ARGO (Array for Real-time Geostrophic Oceanography) profiles. The surface forcing (momentum, heat) is calculated from bulk formulae using 6-hourly atmospheric data from the European Center for Medium Range Weather Forecast (ECMWF). The vertical mixing schemes tested in this study are a second-order statistical model $(\mathrm{k}-\varepsilon)$ and the non-local K-profile parameterization (KPP). Both schemes yield similar results in terms of reproducing the water column dynamics. A major source of discrepancy between model and observations comes from the uncertainties in the atmospheric forcing parameterization. At this point, net shortwave radiation data from NCEP atmospheric 15 reanalysis has been used obtaining a more realistic Sea Surface Temperature (SST) compared with satellite observations for the summer months.

\section{Introduction}

Numerical models of the general circulation of the Mediterranean Sea present large errors in reproducing correctly the vertical structure of the water column. A general difficulty in the models is the reproduction of the shallow surface mixed layer under stable atmospheric forcing conditions (i.e. weak winds and strong surface heating) in the spring-summer seasons. As a consequence, the models tend to overestimates the Sea Surface Temperature (SST) in spring-summer. There are two main reasons that can explain these model errors: the inaccuracy of the surface thermal forcing and the
OSD

3, 1945-1976, 2006

\section{Validation and intercomparison of two vertical-mixing schemes}

V. Fernández et al.

\section{Title Page}


The vertical mixing schemes in ocean models must take into account and parameterize, in the most accurate way possible, a wide range of physical processes that take place in the ocean, e.g.: wind mixing, day-night convection, internal wave mixing, deep convection, etc. Instead, a number of three dimensional Ocean General Circula5 tion Models (OGCM) in the Mediterranean Sea use simplistic vertical mixing schemes, such as constant coefficients for eddy viscosities and diffusivities, or Richardson number based schemes as in the Pacanowsky and Philander (1981) formulation (Tonani et al., 2006 ${ }^{1}$ ). However, there exist a wide range of more sophisticated vertical mixing parameterizations, both statistical closure models (Burchard and Bolding, 2001) and 10 empirical approaches to turbulence (Large et al., 1994; Durski et al., 2004). In this work, as a previous step to their inclusion in a 3-D model, we propose to test the skill of these more advanced turbulence models (not previously implemented in the Mediterranean Sea) to simulate the vertical dynamics of the water column. To achieve this objective, we use the one dimensional General Ocean Turbulence Model (GOTM, see 15 http://www.gotm.net; Umlauf et al., 2005) that is a collection of several vertical mixing schemes, some of which will be tested here.

The first class of models investigated here solves equations for the second moments of fluctuating quantities (e.g. Reynolds stress, turbulent heat flux) occurring due to the decomposition of the flow in to a mean and a fluctuating part. In so-called algebraic second-moment closure models, the dynamic equations describing the evolution of the second moments are simplified such that an algebraic system of equations results. The only prognostic equations solved in these models are an equation for the turbulent inetic energy (TKE), and a second equation describing the evolution of the rate of dissipation, $\varepsilon$ (two-equation models). Due to the number of different parameterizations for the unknown terms, there is a plethora of existing second moment closures. Burchard and Bolding (2001) demonstrated how to include all these different closures consistently into two-equation closure models. A recent review of second-moment closure

\footnotetext{
${ }^{1}$ Tonani, M., Pinardi, N., Dobricic, S., Adani, M., and Fratiani, C.: A high resolution free surface model of the Mediterranean Sea, Ocean Sci. Discuss., submitted, 2006.
}

\section{OSD}

3, 1945-1976, 2006

\section{Validation and intercomparison of two vertical-mixing schemes}

V. Fernández et al.

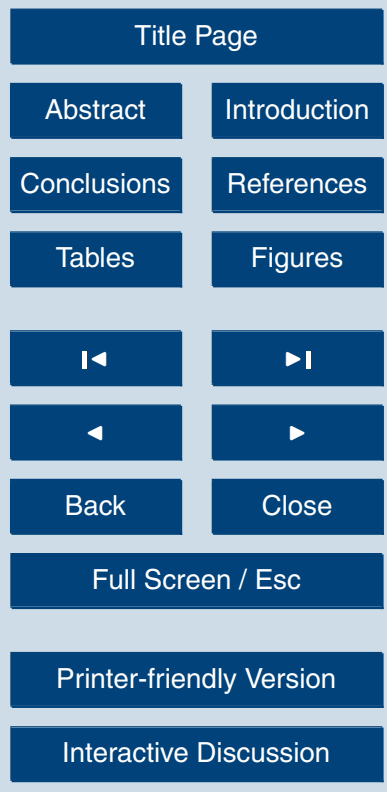

EGU 
models for marine applications is given by Umlauf et al. (2005). It should be noted that these algebraic second-moment closures neglect the non-local effect of turbulent transports.

Compared to the statistical turbulence closure models as the mentioned above, the 5 second mixing scheme used here is the K-Profile parameterization (KPP) model first suggested for the ocean by Large et al. (1994), and later extended by various authors (e.g. Durski et al., 2004). KPP could be called a zeroth-order closure model since it directly calculates the vertical eddy viscosity and diffusivity profiles from available information (density and surface buoyancy fluxes). Due to its empirical character, it is 10 quite easy to include non-local features into the KPP model as already demonstrated by Large et al. (1994). In the ocean interior, mixing is a function of internal wave activity and other processes (e.g. double diffusion) and the eddy coefficient profiles are matched to the mixed layer profiles in a sophisticated way. The KPP model has been incorporated for the first time in GOTM in the framework of the MFSTEP project.

15 The numerical one-dimensional model has been adapted to three geographical locations in the Mediterranean Sea, where there are in-situ vertical profiles of ARGO data available to validate the simulations with the above mixing schemes. The ARGO profilers, which were launched in the Mediterranean in 2004 in the framework of the MFSTEP project, perform a repetitive cycle descending to a prescribed neutral depth 20 (350 $\mathrm{m})$, drift at that level for some time (3-7 days) and then dive down to about $700 \mathrm{~m}$ before ascending to the surface while collecting T/S data. During their short period at surface, the profilers are located, and the data is transmitted to the satellite Argos system. Therefore, they can provide a T/S profile down to a depth of $700 \mathrm{~m}$ with an irregular vertical distribution and a temporal resolution of around 5 days. Besides this data, we also use SST data from satellite to compare the model surface temperature in the simulations.

The paper is structured as follows: in the following chapter we explain the model setup of the model simulations and the vertical mixing schemes used, in chapter three we discuss the model results of the simulations and in the last chapter we draw some

OSD

3, 1945-1976, 2006

\section{Validation and intercomparison of two vertical-mixing schemes}

V. Fernández et al.

Title Page

Abstract Introduction

Conclusions

Tables References Figures

14 $\rightarrow 1$

4

Back

Close

Printer-friendly Version

Interactive Discussion 
conclusions.

\section{Numerical simulations}

\subsection{Model setup}

The water-column model is applied to the three geographical locations shown in Fig. 1 5 that are assimilated as vertical stations. One station is in the Levantine basin (LV) located at $33^{\circ} \mathrm{E}, 33.5^{\circ} \mathrm{N}$; another in the Ionian Sea (IO) at $18^{\circ} \mathrm{E}, 36.5^{\circ} \mathrm{N}$ and the third one in the Gulf of Lions (GL) centered at $3.5^{\circ} \mathrm{E}, 41^{\circ} \mathrm{N}$. At these locations we can assume the effects of lateral advection are relatively small in the first $200 \mathrm{~m}$ as can be seen in Fig. 2 where we show the total heat content down to this depth in the model and 10 in observations. The major mismatch occurs in the GL station in December when there is a large difference between models and data, in the other cases, we can approximate to a one dimensional case considering the effects of lateral advection are not important. Below $200 \mathrm{~m}$ depth, the difference between the model heat content and observations is too large to ignore lateral advection effects. We also have to say that ARGO profiles 15 are not fixed in space, however we have selected the locations where they don't drift too much and therefore we approximate all the measurements are taken in a particular point (Fig. 1) but this can introduce some degree of inaccuracy on the model results.

The vertical grid layout used for the simulations is the same as the one used in the OGCM_MFSTEP Mediterranean model (Tonani et al., $2006^{1}$ ), because our ultimate goal is to include the vertical mixing schemes into a three dimensional OGCM. The layer thickness is unevenly distributed and varies from $3 \mathrm{~m}$ at the surface to $45 \mathrm{~m}$ at the bottom (See Fig. 3 showing the layer thicknesses distribution).

Initial conditions for temperature and salinity are taken from a particular ARGO cast. In the LV station, we initialize the model the first of January of year 2004; for the IO the initial time is the 3 January and for the GL the initialization is done at the 5 July, always of year 2004 .

\section{OSD}

3, 1945-1976, 2006

Validation and intercomparison of two vertical-mixing schemes

V. Fernández et al.

Title Page

Abstract Introduction

Conclusions

References

Tables Figures



$\rightarrow 1$

Back

Close

Printer-friendly Version

Interactive Discussion 
As surface boundary conditions for momentum and temperature we use bulk formulae from Kondo (1975) for which we took the $10 \mathrm{~m}$ wind velocity vector, the $2 \mathrm{~m}$ dry air temperature, the $2 \mathrm{~m}$ dew point temperature, the $2 \mathrm{~m}$ air pressure and the sea surface temperature from the one-dimensional model as input. The meteorological data comes 5 from the ECMWF reanalysis used in the MFSTEP system (Tonani et al., $2006^{1}$ ). It is important to say that here that there is a relative degree of inaccuracies in the surface fluxes parameterization, and therefore, it is difficult sometimes to separate the test of the model skill and the accuracy of the surface forcing. As an example of this we have found that using the classical bulk formulae for the short wave radiation, the model pre10 dicts very high surface temperatures in the summer and this error can be diminished using forcing data directly from a radiative atmospheric model (see a discussion in Appendix A). Therefore, we have used for all the simulations presented here the incident shortwave radiation from NCEP reanalysis (http://www.cdc.noaa.gov/). Solar extinction corresponding to the type I waters of Jerlov was used with the same empirical values 15 as Paulson and Simpson (1977).

For the freshwater fluxes we have used a nudging towards observed salinity within the upper layer of the model at a time scale of 1 day.

A time step of $600 \mathrm{~s}$ was used, which is the same as in the MFSTEP_OGCM model.

\subsection{The vertical mixing schemes}

\subsubsection{The second-moment closure model}

The second-moment closure model is used here with a steady-state Richardson number of 0.25 (Burchard and Bolding, 2001) and the algebraic second-moment closure by Cheng et al. (2002). Additionally, the simple length scale limitation suggested by Galperin et al. (1988) and Luyten et al. (1997) with a minimum TKE of $\mathrm{k}_{\min }=10^{-7} \mathrm{~J} \mathrm{Kg}^{-1}$

was applied. It is easy to show that this length scale limitation implies that the turbulent diffusivity is proportional to $k_{\min } N^{-1}$, where $N$ denotes the buoyancy frequency. If $k_{\min }$ is identified with the kinetic energy of internal waves, assumed to be constant and uni-
OSD

3, 1945-1976, 2006

\section{Validation and intercomparison of two vertical-mixing schemes}

V. Fernández et al.

Title Page

Abstract Introduction

Conclusions

Tables

References

Figures

14

$\rightarrow 1$

4

Back

Close

Printer-friendly Version

Interactive Discussion 
form in this simple approach, then the length scale limitation can be interpreted as a frequently used model for vertical mixing due to internal wave motion (see e.g. Lass et al., 2003).

OSD

3, 1945-1976, 2006

\subsubsection{The KPP turbulence model}

5 The K-profile parameterization of Large et al. (1994) distinguishes between an "oceanic planetary surface boundary layer" and the ocean interior. In the boundary layer, which is basically the depth at which eddies penetrate in the vertical; a formulation based on boundary layer similarity theory is applied. This is matched at the base of the boundary layer with mixing formulations to account for local shear and internal wave effects.

10 The depth of the boundary layer $\left(\mathrm{h}_{b}\right)$ is computed numerically as the position that a bulk Richardson number, as defined by Large et al. (1994), exceeds a critical value $\left(R i_{c}\right)$. The way the interpolation is done to evaluate $h_{b}$ is grid-depending, a difficulty that cannot be overcome with the KPP model. In the ocean interior (i.e. outside the surface boundary layer), KPP estimates the viscosity coefficient taking into account the effects of shear mixing and internal wave-breaking generated mixing (along with double-diffusive mixing that is set to zero in this study). The KPP model was used here with interior mixing and non-local mixing, but without bottom module. Also the doublediffusive mixing parameterization for the interior is also excluded. Finally, the boundary layer is cut if it exceeds the Ekman or the Monin-Obukhov length scale.

20 The KPP model has a large number of empirical adjustable parameters, both for the surface boundary layer and for the interior mixing below. We have chosen for this study, the same range of values suggested for the Ocean Weather Station Papa in Large et al. (1994). Some of these parameters are listed in Table 1.

A more detailed description on the numerical implementation of the second-moment 25 and KPP turbulence models can be found in the GOTM documentation (http://www. gotm.net; Umlauf et al., 2005).

\section{Validation and intercomparison of two vertical-mixing schemes}

V. Fernández et al.

\section{Title Page}




\section{Model results}

\subsection{Comparison with observations}

For each of the three stations considered in this study, two simulations have been compared (second-moment model and KPP), forced with the same atmospheric forcing. In

5 Figs. 4, 5 and 6, the temporal evolution of temperature for both, models and observations, is shown.

It can be seen that, at the three locations, both vertical mixing schemes reproduce quite well the temperature evolution given by the observations. The main difference between the observations and the model is the absence of the wavy structure at the base of the thermocline (present only in the observations). This structure is most likely due to three dimensional horizontal advection effects, obviously not reproducible by a one-dimensional configuration.

In the LV and IO stations (those with the longest time series of observations to compare), we can see that the models correctly predict the onset of stratification in spring, the maintenance in summer, and the thermocline erosion in autumn. In the case of the LV station, we can see that both turbulence closure models under-predict the summer surface mixed layer (see the mixed layer depth between 22 July 2004 and 10 September 2004 in Fig. 4). Mixing is slightly deeper in the case of the KPP simulation.

In order to quantitatively assess the performance of each model, we computed the

Root Mean Square (RMS) of the misfit between model and observations for each profile. For doing this we interpolated the model temperature to the depth of each ARGO casts and computed the model-data misfit. As long as each particular ARGO cast has different vertical distribution of depths, we divided the water column into a range of vertical levels and then we computed the RMS of all the misfits at depths that fall for each range. The distribution of vertical levels to compute the RMS of the misfit starts at $5 \mathrm{~m}$ and the thickness is $10 \mathrm{~m}$ down to $100 \mathrm{~m}$ deep, and below this depth the level thickness is $100 \mathrm{~m}$ until the bottom of the profile.

Displayed in Figs. 7, 8 and 9 are the corresponding vertical profiles of the RMS of

\section{Validation and intercomparison of two vertical-mixing schemes \\ V. Fernández et al.}

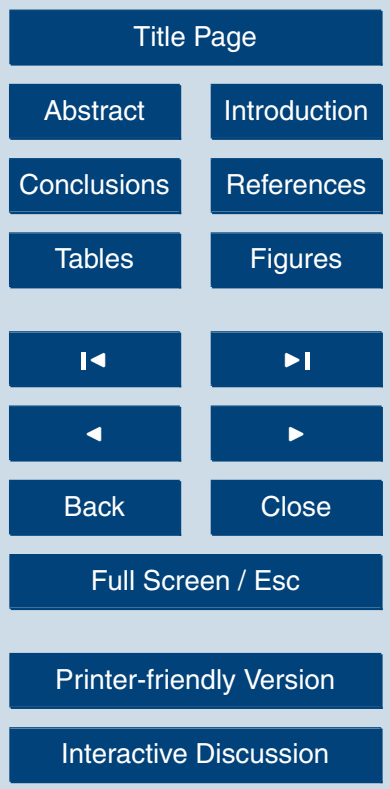

EGU 
the misfit, averaged for all the period of the simulation. In the eastern basin stations (IO and LV), we observe two local maxima, one at depths between $300 \mathrm{~m}$ and $400 \mathrm{~m}$ probably due to lateral advection of LIW (Levantine Intermediate Waters) present at this depth (Robinson et al., 1991) and another at depths above $50 \mathrm{~m}$ corresponding to 5 the spring-summer surface shallow thermocline. In the LV station, we can say that the KPP model reduces the surface error by around $40 \%$. For the other two stations both mixing schemes yield fairly similar results with a slightly superior representation in the KPP simulation above $\sim 100 \mathrm{~m}$.

In Fig. 10 we can see the temporal evolution of the RMS between 35 and $45 \mathrm{~m}$ depth 10 in the LV station. It can be seen that the error in the summer months is reduced in the KPP simulation. One plausible reason for this improvement is the inclusion of the internal wave mixing parameterization in KPP. This is one of the main physical processes for mixing under stable stratification during the summer months; therefore its inclusion in vertical mixing schemes is important as already shown in (Kantha and Clayson, 1994).

15 In the second-moment closure this internal wave mixing is parameterized by the length scale limitation given by the parameter $k_{\min }$, however, we haven't found important differences when modifying this parameter (see Sect. 3.3).

\subsection{Mixing diffusivities and viscosities}

In Figs. 11 and 12 we show a comparison of eddy diffusivity and viscosity profiles, 20 together with temperature and velocities, for a particular summer date (5 August) in the LV station. It is evident that in the surface boundary layer the values of viscosity and diffusivity are similar, but at the base of the mixed layer, the values computed by the KPP model are larger than in the second-moment closure model. This is a clear indicated for suppressed entrainment and surface layer deepening, and thus in accordance with the result in presented in Sect. 3.1.

To gain further insight into the behavior of both mixing schemes, we have studied the daily cycle of temperature and eddy diffusivities in the LV station. The resolution of the daily cycle allowed us to study quantitative differences of model behavior during the two

OSD

3, 1945-1976, 2006

\section{Validation and intercomparison of two vertical-mixing schemes \\ V. Fernández et al.}



EGU 
main dynamical regimes of mixed layer deepening: wind mixing and night convection. Enhanced mixing during night convection is predicted by models, as visible in Figs. 13 and 14. However, it is also evident that the night convection mixes down to $\sim 20 \mathrm{~m}$ in KPP model (Fig. 12), whereas it reaches only $\sim 15 \mathrm{~m}$ in the second-moment closure.

5 As a general behavior, mixing is small when there is more heating from the sun and larger during the night hours (18:00 and 00:00).

\subsection{Sensitivity experiments}

We have performed some experiments to test the sensitivity of the KPP model to changes in the adjustable parameters in Table 1. We have done these experiments in the LV station which is the one with the longest time series to compare the results. The main result from the experiments is that the KPP results are sensible to the values of the background diffusivities below the mixed layer. The larger the values are, the closer to observations the predicted model temperatures are. Furthermore it can be seen in Fig. 15 that the error in the first $100 \mathrm{~m}$ is smaller when using higher values of background viscosity and diffusivity.

In the second-moment model, we have studied the sensitivity to the minimum TKE $\left(\mathrm{k}_{\min }\right)$, which is a tuning parameter that can account for the internal wave mixing, which is important for the summer mixed layer. We can see in Fig. 16 that increasing the value from the standard $10^{-7} \mathrm{~J} / \mathrm{Kg}$ to $10^{-5} \mathrm{~J} / \mathrm{Kg}$, the results improve below $150 \mathrm{~m}$ and that there is no difference between using $10^{-7} \mathrm{~J} / \mathrm{Kg}$ or $10^{-6} \mathrm{~J} / \mathrm{Kg}$.

\section{Conclusions}

In this study we have implemented, tuned and validated against observations in the Mediterranean Sea two different kind of vertical mixing parameterizations: a statistical second-moment closure model and an empirical model (KPP).

The main conclusion inferred from the study is that both models compute rather sim-

OSD

3, 1945-1976, 2006

Validation and intercomparison of two vertical-mixing schemes

V. Fernández et al.

Title Page

Abstract Introduction

Conclusions

References

Tables Figures

14 $\rightarrow 1$

4

Back

Close

Printer-friendly Version

Interactive Discussion 
ilar temperature profiles if starting from the same initial conditions and using identical atmospheric forcing. It can be seen that they represent quite well the observed temperature profiles without any kind of restoring, taking into account the absence in the simulations of horizontal advection effects, and the dispersion of the observations, that

5 are not all taken at the same point. They are also able to reproduce quite well the seasonal variability as well as the diurnal cycling of temperature. These results may indicate that if implemented in a Mediterranean Sea OGCM, we would not expect large differences between these two different turbulence closure schemes. It seems, however, that the KPP model predicts slightly deeper mixed layers in summer, and this 10 encourages us to better test this result in a 3-D configuration. Actually, the OPA-GOTM coupling is being performed to better validate qualitatively the second-moment ant the KPP mixing models in the Mediterranean Sea.

We have also found that, besides the closure schemes used, the model SST is rather sensitive to the parameterization of the incident short wave radiation. We recommend 15 here the use of direct fluxes from an atmospheric model instead of bulk formulae that introduce many approximations.

As a final remark, we have to say that the CPU requirements for the two model simulations are comparable, and we would not expect significant performance differences for the two turbulence closure schemes when embedded into an OGCM. On the other hand, the second-moment model requires more memory, since two additional threedimensional fields have to be stored.

\section{Appendix A}

\section{The radiative fluxes}

25 The solar radiation flux is the largest atmospheric component in the heat budget of the ocean and therefore it is desirable to adequately represent it in ocean models in order to get a correct SST. The incident shortwave net radiation computed in the MFSTEP

\section{OSD}

3, 1945-1976, 2006

\section{Validation and intercomparison of two vertical-mixing schemes}

V. Fernández et al.

\section{Title Page}

\section{Full Screen / Esc}

Printer-friendly Version

Interactive Discussion 
ocean model by using empirical bulk formulae depending on the geographical position (longitude and latitude), cloud cover and albedo. The albedo monthly values comes from Payne (1972) table and were given as means of the values between at $30 \mathrm{~N}$ and $40 \mathrm{~N}$ for the Atlantic Ocean (hence the same latitudinal band of the Mediterranean 5 Sea). The basic formula for the short-wave radiation at the surface has been taken from Rosati and Miyakoda (1988), who adapted the work of Reed (1977) and Paulson and Simpson (1977). You can see a more detailed description of the bulk formulae used in the work by Castellari et al. (1998). These bulk formulae rely on several crude approximations. For example, the effect of a realistic distribution of aerosols is not 10 taken into account, and neither the type of clouds. Also, the empirical coefficients in Reed (1977) have been computed originally for the Pacific Ocean. Therefore, it is not too strange that they are inaccurate in the Mediterranean Sea.

Beside empirical bulk formula, meteorological predictive models can provide estimates of solar irradiance by using rather accurate atmospheric radiative transfer models. An example is the net shortwave radiation flux data from the NCEP Atmospheric Reanalysis provided by the NOAA-CIRES Climate Diagnostics Center, Boulder, Colorado, USA, from their Web site at http://www.cdc.noaa.gov/.

Here we asses the validity of the bulk formulae and the radiative fluxes by comparing the SST resulting from two different radiative fluxes: the bulk formulae and the NCEP 20 forcing radiation. The model results are validated with independent data from satellite. The satellite comes from an optimal interpolation daily reanalysis produced by ENEA (Progetto Speciale Clima Globale) and Gruppo Oceanografia da Satellite (GOS) of the CNR-ISAC. We can see in Fig. A1 that the SST obtained when forcing the model with the radiative NCEP fluxes is closer to satellite observations in the three stations studied 25 here.

Acknowledgements. This work has been prepared in the framework of the EU-funded Integrated project MFSTEP (Medtiterranean Forecasting System. Towards Environmental Prediction, EU, contract number, EVK3-CT-2002-00075) as part of a subcontract between the INGV (Bologna, Italy) and Bolding \& Burchard Hydrodynamics GbR (Rostock, Germany).
OSD

3, 1945-1976, 2006

\section{Validation and intercomparison of two vertical-mixing schemes}

V. Fernández et al.

Title Page

Abstract Introduction

Conclusions

Tables References Figures

14 $\rightarrow 1$

4

Back

Close

Printer-friendly Version

Interactive Discussion 


\section{References}

Burchard, $\mathrm{H}$. and Bolding, K.: Comparative analysis of four second-moment turbulence closure models for the oceanic mixed layer, J. Phys. Oceanogr., 31, 1943-1968, 2001.

Cheng, Y., Canuto, V. M., and Howard, A.: An improved model for the turbulent PBL, J. Atmos. Sci , 59, 1550-1565, 2002.

Galperin, B., Kantha, L. H., Hassid, S., and Rosati, A.: A quasi-equilibrium turbulent energy model for geophysical flows, J. Atmos. Sci., 45, 55-62, 1988.

Kantha, L. H. and Clayson, C. A.: An improved layer model for geophysical applications, J. Geophys. Res., 99(C12), 25235-25266, 1994.

10 Kondo, J.: Air-Sea bulk transfer coefficients in diabatic conditions, Bound. Layer Meteorol., 9, 91-112, 1975.

Large, W. G., McWilliams, J. C., and Doney, S. C.: Oceanic vertical mixing: a review and a model with nonlocal boundary layer parameterization, Rev. Geophys., 32, 363-403, 1994

Lass, U., Prandke, H., and Liljebladh, B.: Dissipation in the Baltic proper during winter stratification, J. Geophys. Res., 108(C6), 3187, doi:10.1029/2002JC001401, 2003.

Luyten, P. J., Simpson, J. H., and Rippeth, T. P.: Comparison of turbulence models for homogeneous and stratified flows with turbulence measurements in the Irish Sea, MAST Workshop on Turbulence Modelling in Bergen, Norway, 8-10 August 1996.

Paulson, C. A. and Simpson, J. J.: Irradiance measurements in the upper ocean, J. Phys. Oceanogr., 7, 952-956, 1977.

Reed, R. K.: On estimating insolation over the ocean, J. Phys. Oceanogr., 7, 482-485, 1977.

Robinson, A. R., Golnaraghi, M., Leslie, W. G., Artegiani, A., Hecht, A., Lazzoni, E., Michelato, A., Sansone, E., Theocharis, A., and Unluata, U.: The Eastern Mediterranean General Circulation: Features, Structure and Variabiliy, Dyn. Atmos. Oceans, 15(3-5), 215-240, 1991.

Rosati, A. and Miyakoda, K.: A general circulation model for upper ocean simulation, J. Phys. Oceanogr., 18, 1601-1626, 1988.

Umlauf, L. and Burchard, H.: A generic length-scale equation for geophysical turbulence models, J. Mar. Res., 61, 235-265, 2003.

Umlauf, L. and Burchard, H.: Second-order turbulence closure models for geophysical boundary layers. A review of recent work, Cont. Shelf Res., 25, 795-827, 2005.

Umlauf, L., Burchard, H., and Bolding, K.: GOTM - Sourcecode and Testcase documentation, Version 3.2, Meereswiss. Ber., 63, Baltic Sea Research Institute, Warnemünde, Germany,

\section{Validation and intercomparison of two vertical-mixing schemes}

V. Fernández et al.

Title Page

Abstract Introduction

Conclusions

References

Tables Figures

14

4

Back

Full Screen / Esc

Printer-friendly Version

Interactive Discussion 


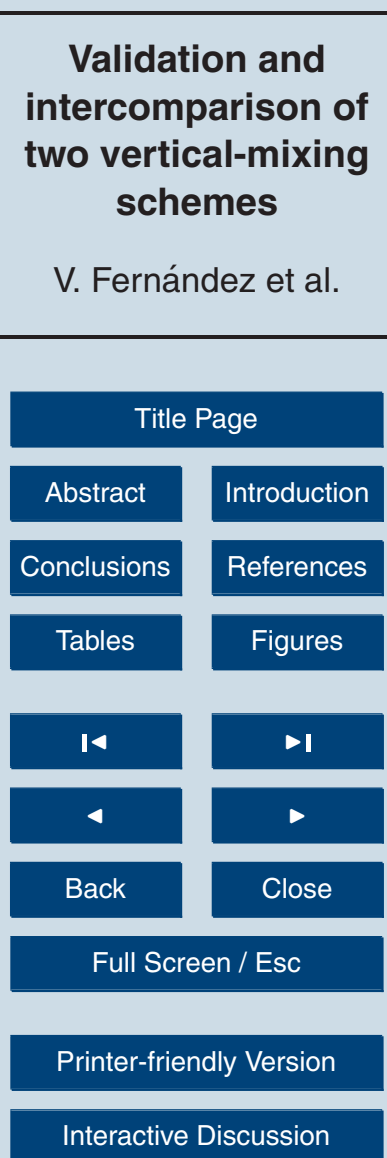


OSD

3, 1945-1976, 2006

\section{Validation and intercomparison of two vertical-mixing schemes}

V. Fernández et al.

Table 1. Values of the coefficients used in the KPP simulations in this study.

\begin{tabular}{llllll}
\hline $\mathrm{C}_{v}$ & $\mathrm{Ri}_{c}$ & $v_{m}^{w}\left(\mathrm{~m}^{2} \mathrm{~s}^{-1}\right)$ & $v_{s}^{w}\left(\mathrm{~m}^{2} \mathrm{~s}^{-1}\right)$ & $v_{0}\left(\mathrm{~m}^{2} \mathrm{~s}^{-1}\right)$ & $\mathrm{Ri}_{0}$ \\
\hline 1.5 & 0.4 & $10^{-4}$ & $10^{-5}$ & $50 \times 10^{-4}$ & 0.7
\end{tabular}

Title Page

Abstract

Conclusions

Tables

14

Back

Full Screen / Esc

Printer-friendly Version

Interactive Discussion 


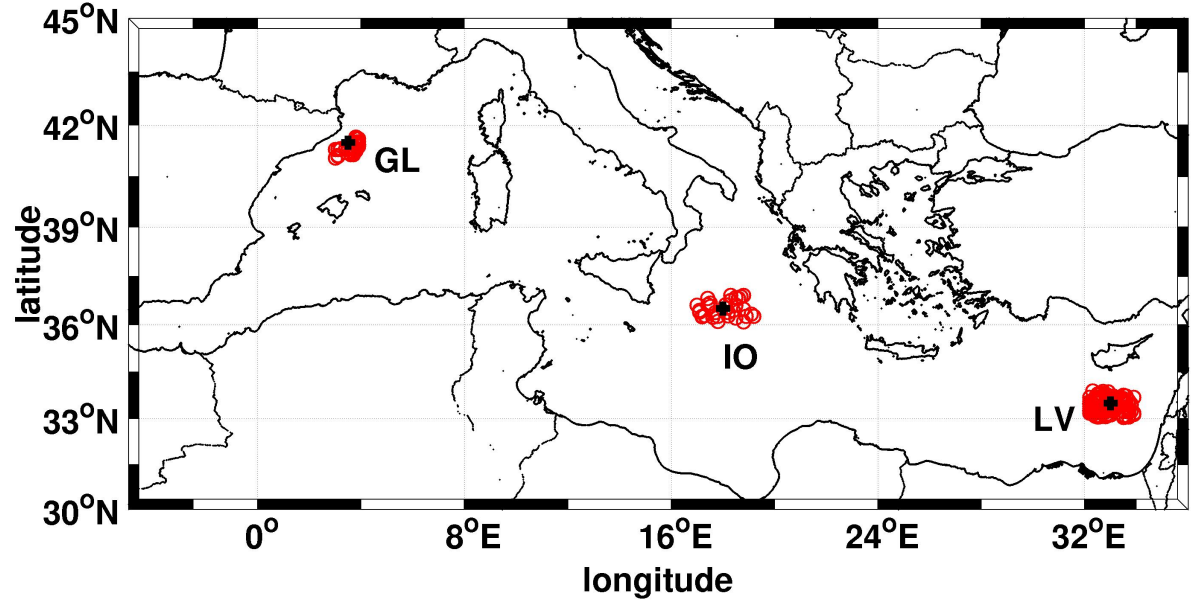

Fig. 1. Map showing the three Mediterranean locations where the column model is applied. The red circles are the ARGO profiles and the black crosses are the position of the stations.

\section{Validation and intercomparison of two vertical-mixing schemes}

V. Fernández et al.

Title Page

Abstract Introduction

Conclusions

References

Tables

Figures

14

$\rightarrow 1$

4

Back

Close

Full Screen / Esc

Printer-friendly Version

Interactive Discussion 

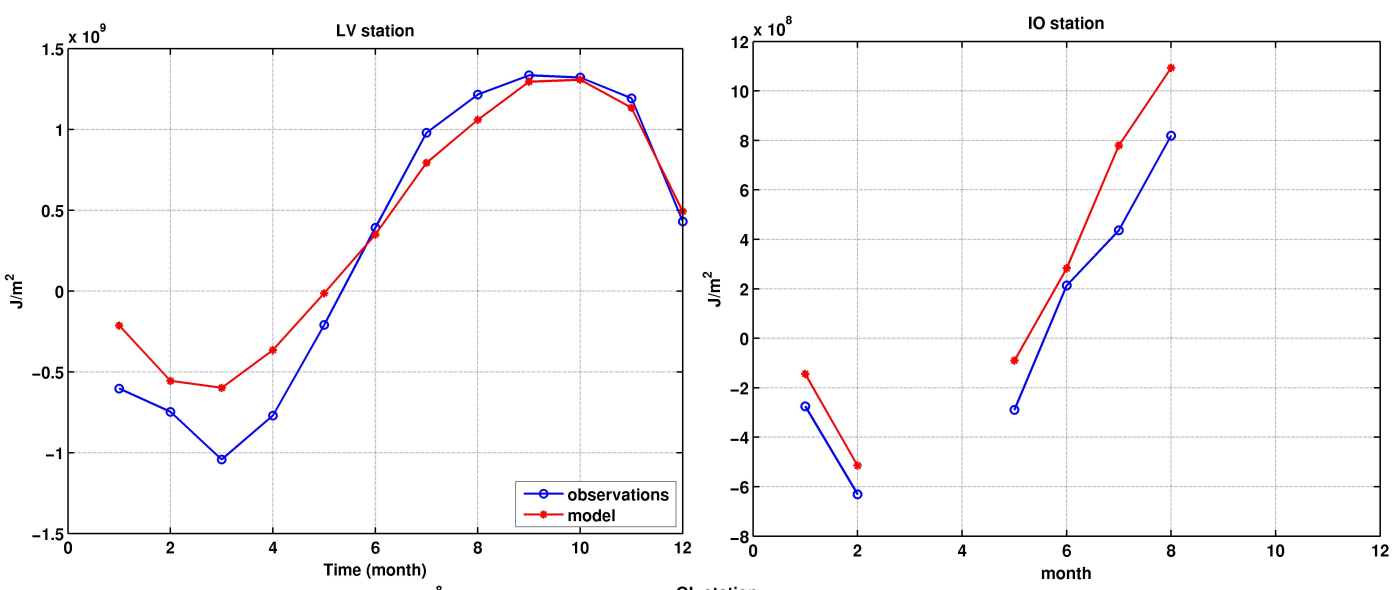

OSD

3, 1945-1976, 2006

\section{Validation and intercomparison of two vertical-mixing schemes}

V. Fernández et al.

Title Page

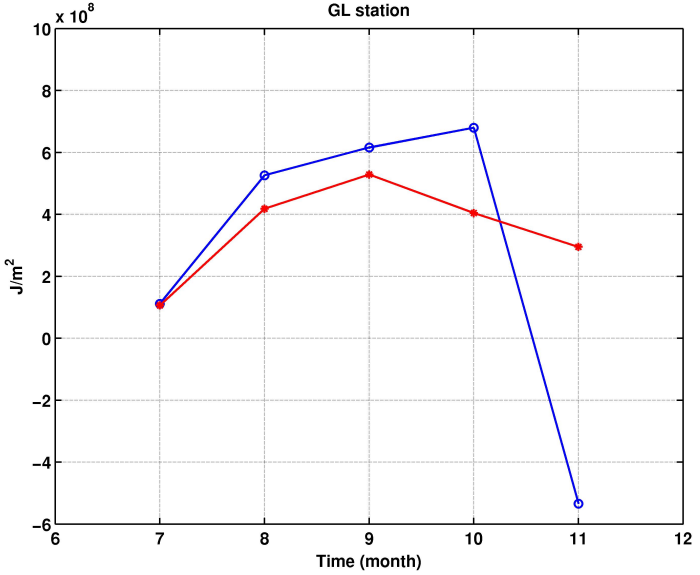

Abstract

Introduction

Conclusions

References

Tables

Figures

14

4

Back

Close

Full Screen / Esc

Printer-friendly Version

Fig. 2. Monthly average heat content (computed with respect to the initial temperature profile from observations) down to $200 \mathrm{~m}$ for the three stations.

Interactive Discussion 


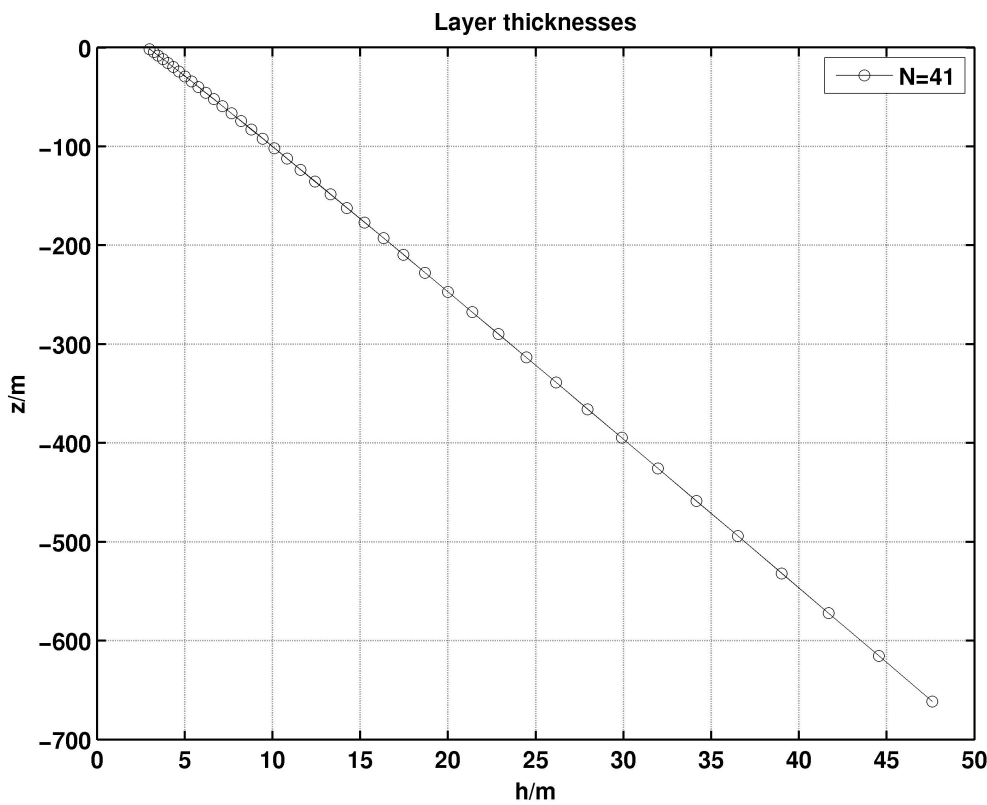

Fig. 3. Layer thicknesses for the GOTM experiments with 41 layers. The distribution of layer thickness is the same as in the MFSTEP OPA system.

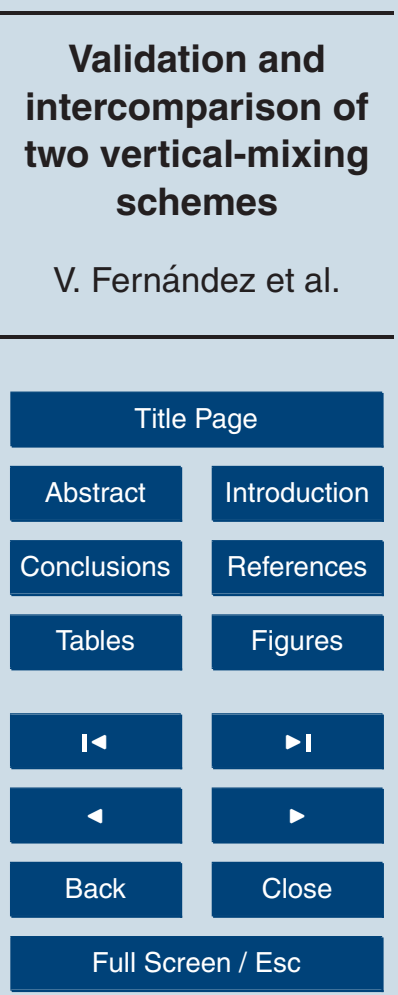

Printer-friendly Version

Interactive Discussion 

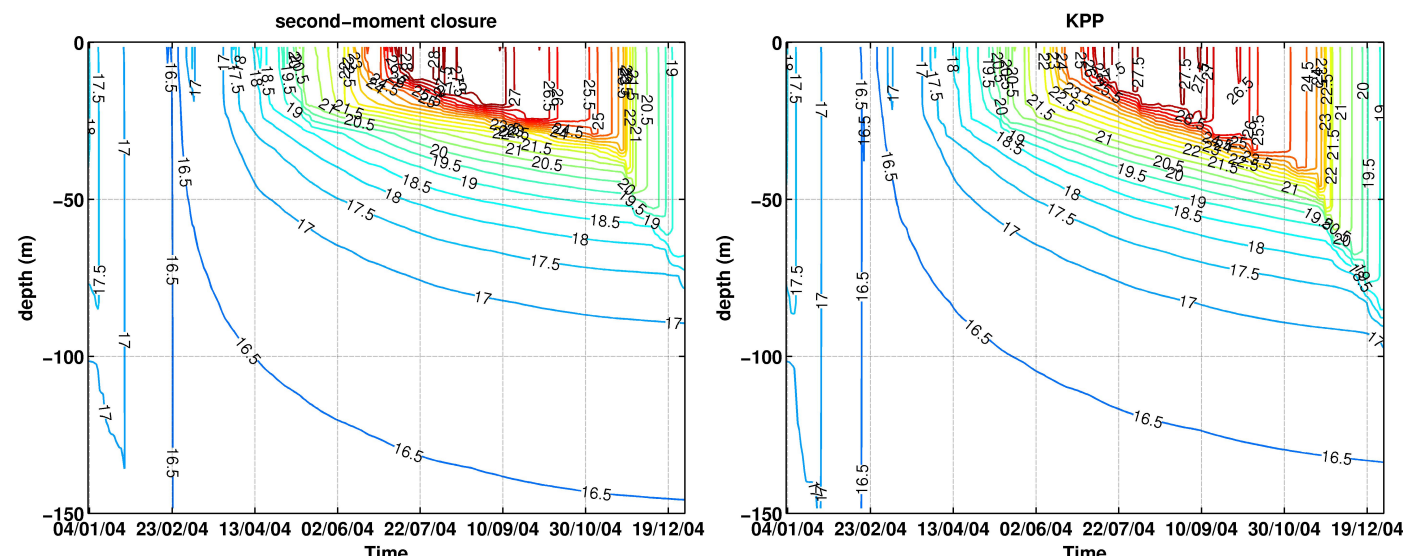

Time Time

Observations

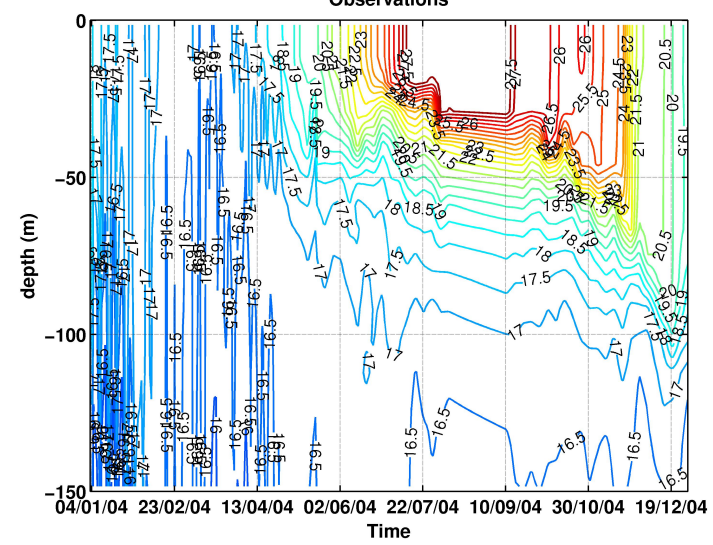

OSD

3, 1945-1976, 2006

\section{Validation and intercomparison of two vertical-mixing schemes}

V. Fernández et al.

Title Page

Abstract

Conclusions

Tables

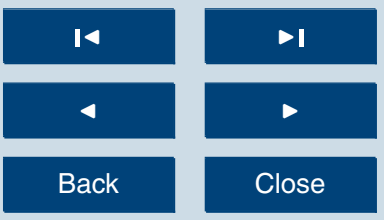

Full Screen / Esc

Printer-friendly Version

Interactive Discussion model; middle panel is KPP and bottom panel are observations (linearly interpolated in time). For clarity, only the upper $150 \mathrm{~m}$ are shown. 



OSD

3, 1945-1976, 2006

\section{Validation and intercomparison of two vertical-mixing schemes}

V. Fernández et al.



Title Page

Abstract

Introduction

Conclusions

References

Tables

Figures

14

- I

4

Back

Close

Full Screen / Esc

Fig. 5. Temperature simulations for the $1 \mathrm{O}$ station in 2004. Upper panel is the second-moment model; middle panel is KPP and bottom panel are observations (linearly interpolated in time). For clarity only the upper $150 \mathrm{~m}$ are shown.

Printer-friendly Version

Interactive Discussion 

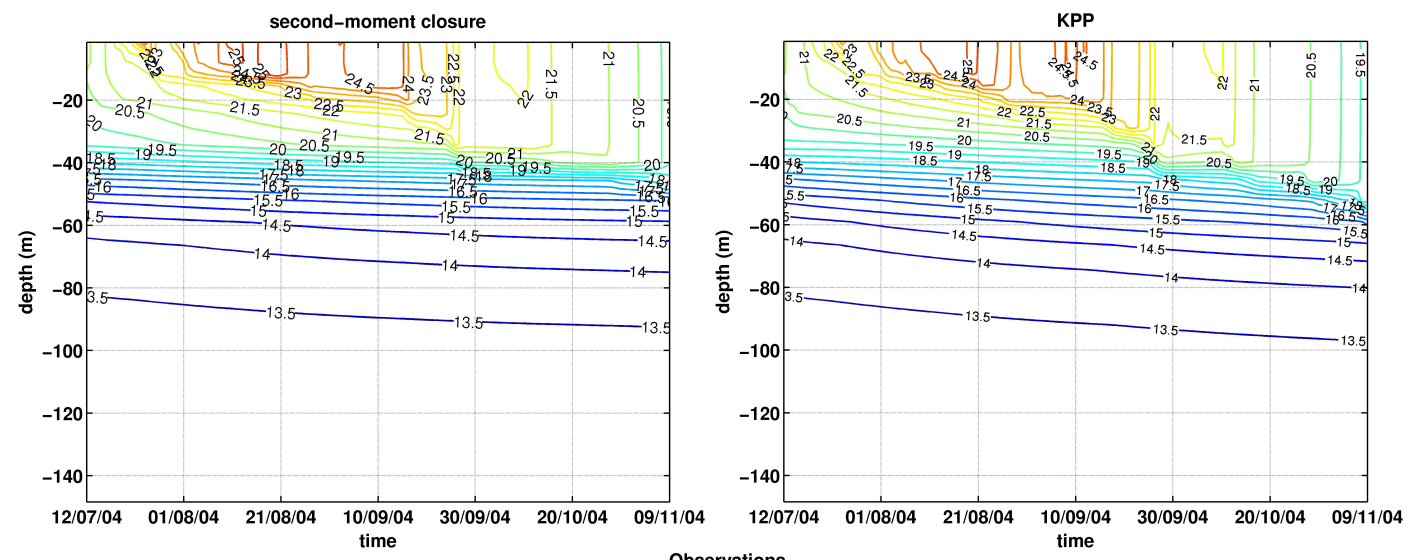

Observation

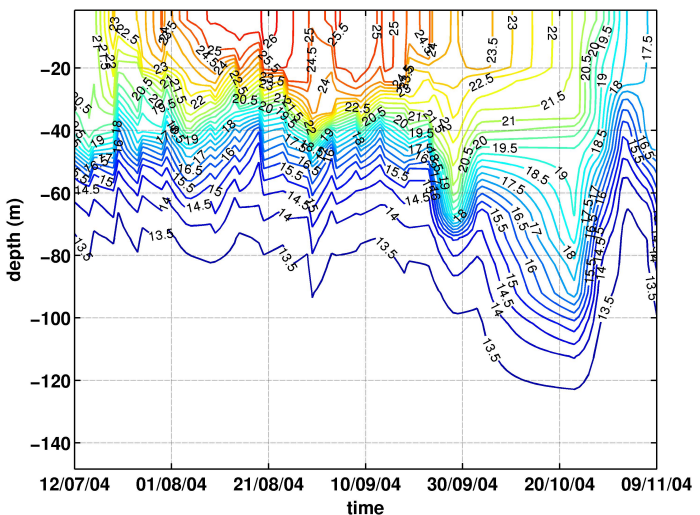

time

Fig. 6. Temperature simulations for the GL station in 2004. Upper panel is the second-moment model; middle panel is KPP and bottom panel are observations (linearly interpolated - in time).
OSD

3, 1945-1976, 2006

\section{Validation and intercomparison of two vertical-mixing schemes}

V. Fernández et al.

Title Page

Abstract

Introduction

Conclusions

References

Tables

Figures

14

- I

4

Back

Close

Full Screen / Esc

Printer-friendly Version

Interactive Discussion 


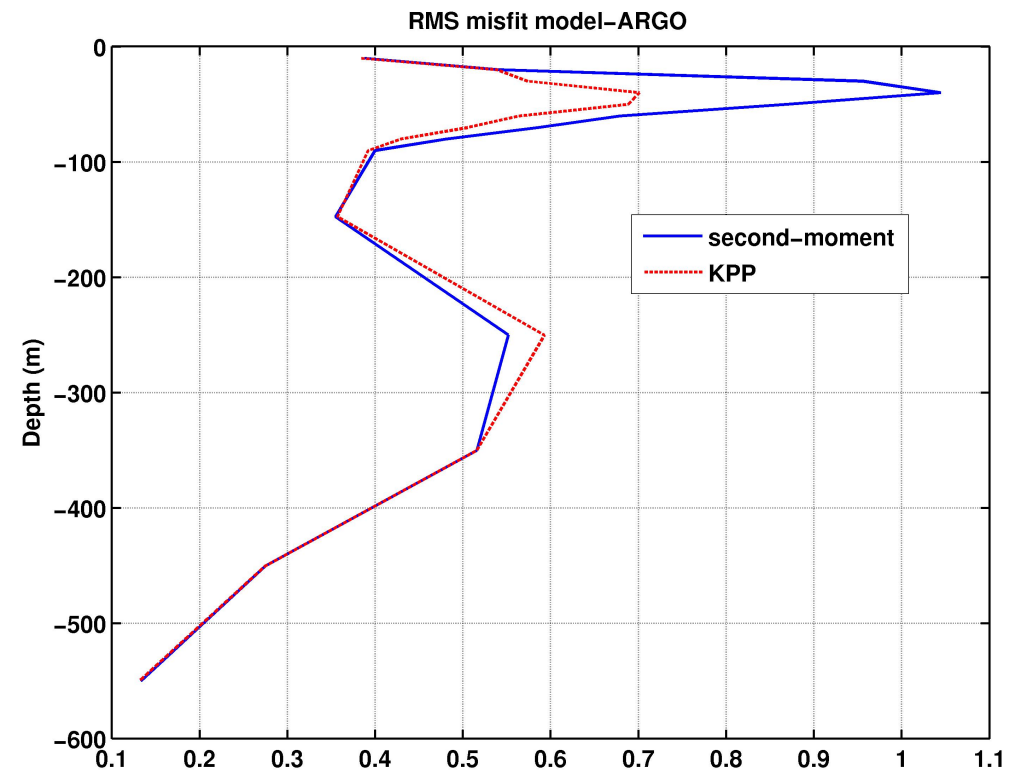

\section{Validation and intercomparison of two vertical-mixing schemes}

V. Fernández et al.

Title Page

Abstract

Conclusions

Tables

14

4

Back

Full Screen / Esc

Printer-friendly Version

Interactive Discussion 


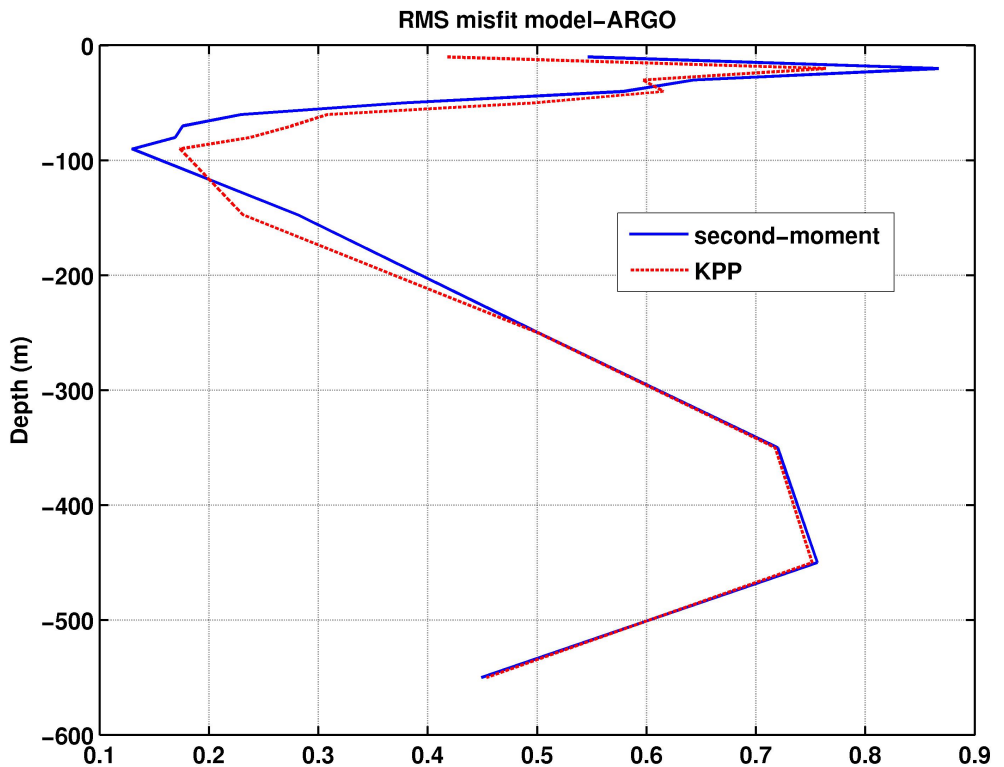

\section{Validation and intercomparison of two vertical-mixing schemes}

V. Fernández et al.

Title Page

Abstract

Conclusions

Tables

14

4

Back

Full Screen / Esc

Printer-friendly Version

Interactive Discussion 


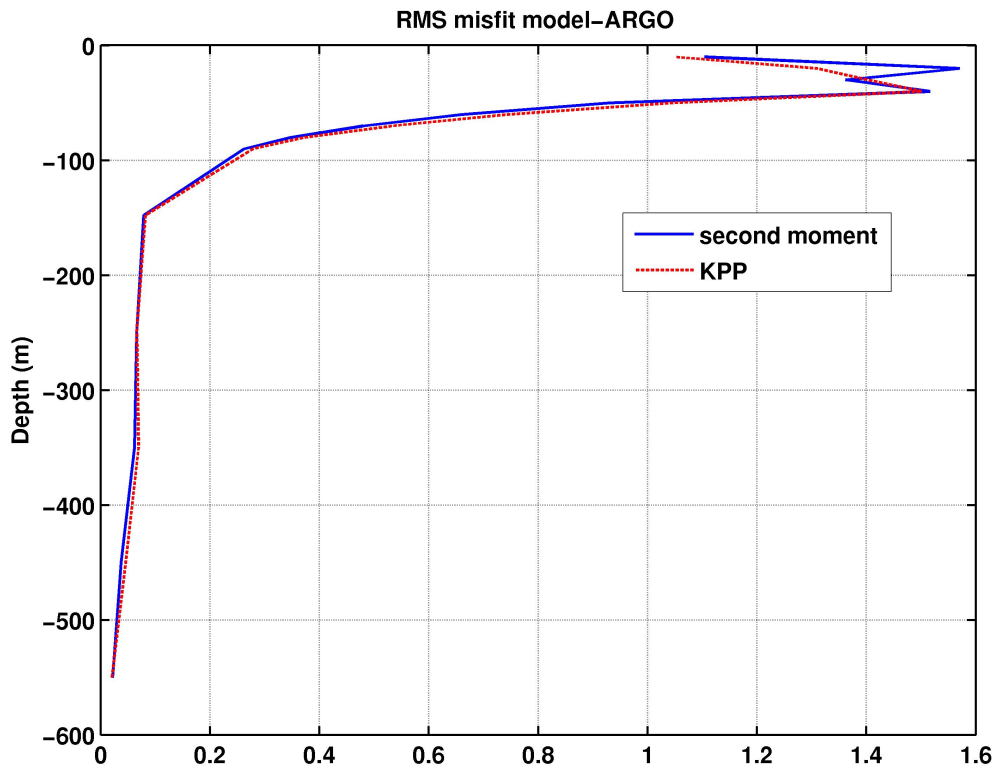

\section{Validation and intercomparison of two vertical-mixing schemes}

V. Fernández et al.

Title Page

Abstract

Conclusions

Tables

14

Back

Full Screen / Esc

Printer-friendly Version

Interactive Discussion 


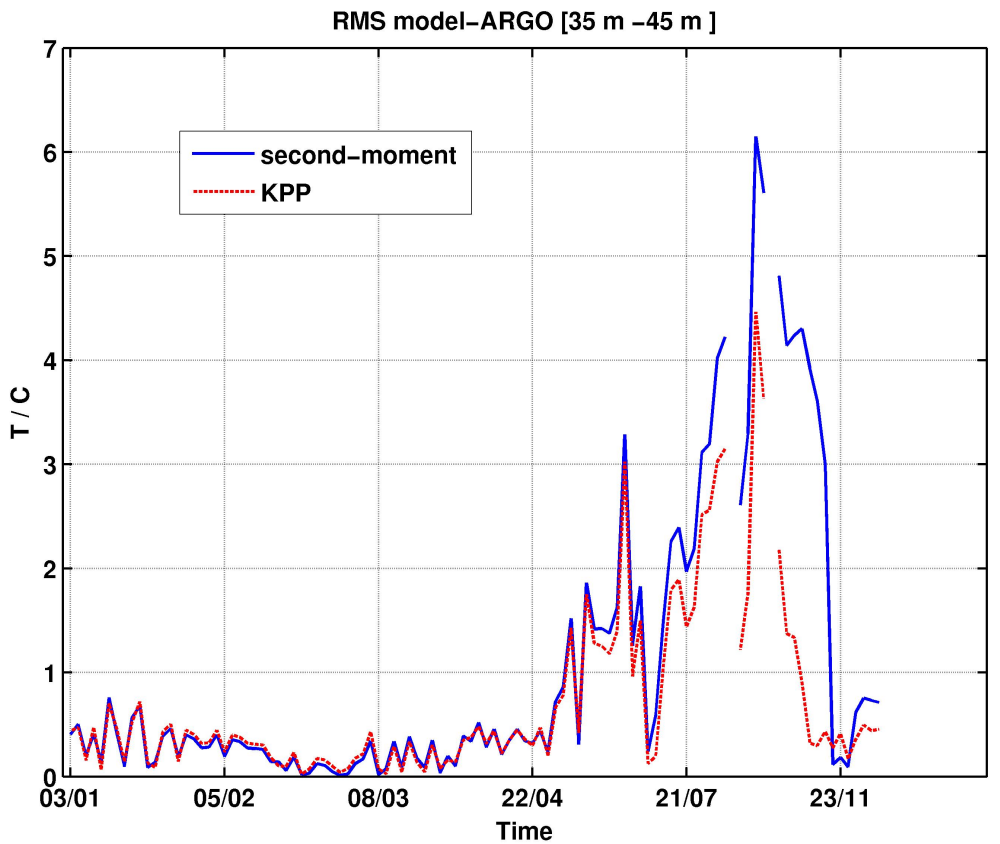

Fig. 10. Temporal evolution of the RMS of the misfit of temperature between 35 and $45 \mathrm{~m}$ depth for the two vertical mixing schemes.

\section{Validation and intercomparison of two vertical-mixing schemes}

V. Fernández et al.

Title Page

Abstract Introduction

Conclusions

References

Tables

Figures

14



Back

Full Screen / Esc

Printer-friendly Version

Interactive Discussion 

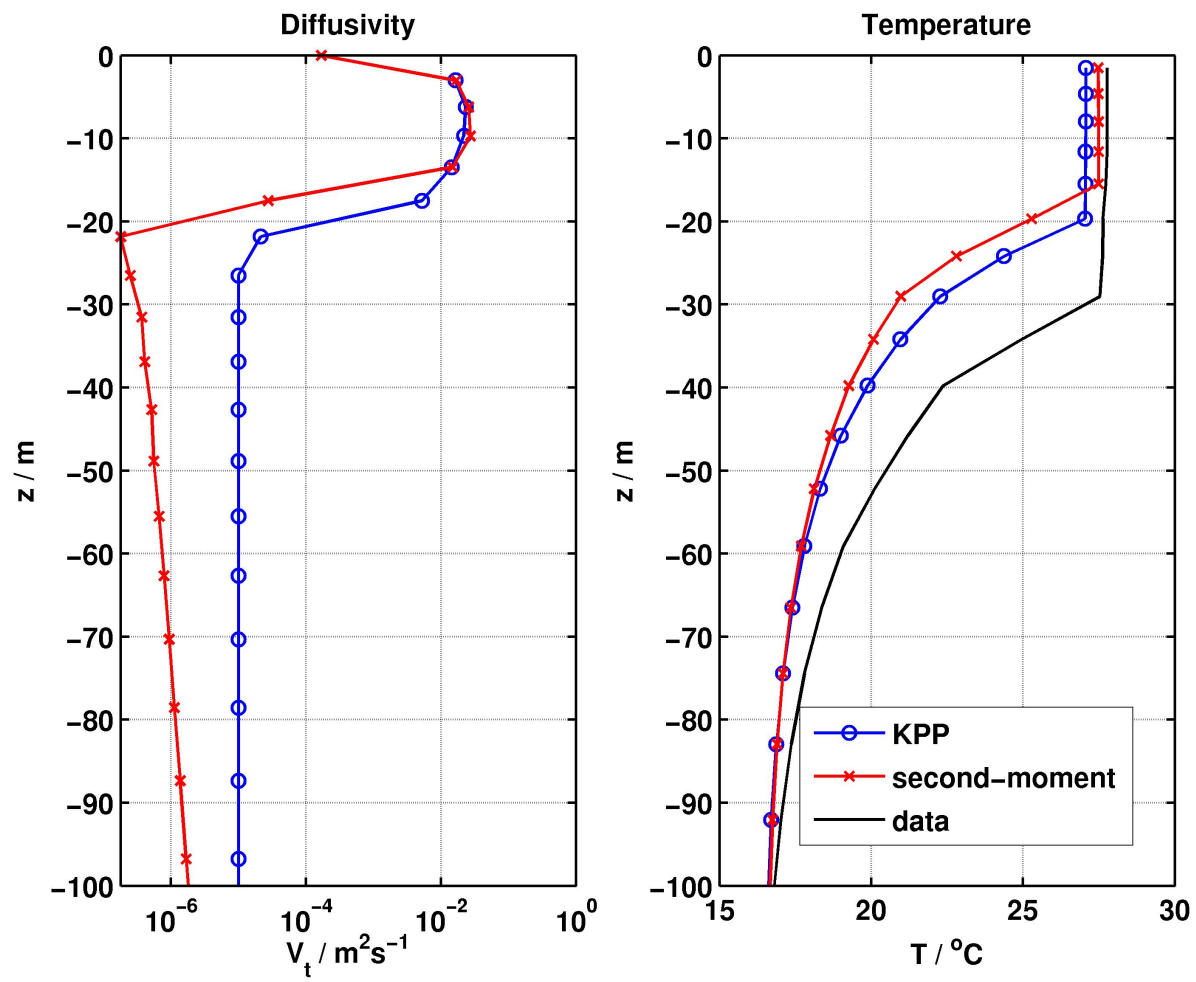

\section{3, 1945-1976, 2006}

\section{Validation and intercomparison of two vertical-mixing schemes}

V. Fernández et al.

Title Page

Abstract

Conclusions

Tables

14

4

Back

Full Screen / Esc

Fig. 11. Temperature and eddy diffusivity profiles from simulations in the LV station on 5 August 2004. The ARGO observed profile is also shown.
Printer-friendly Version

Interactive Discussion 

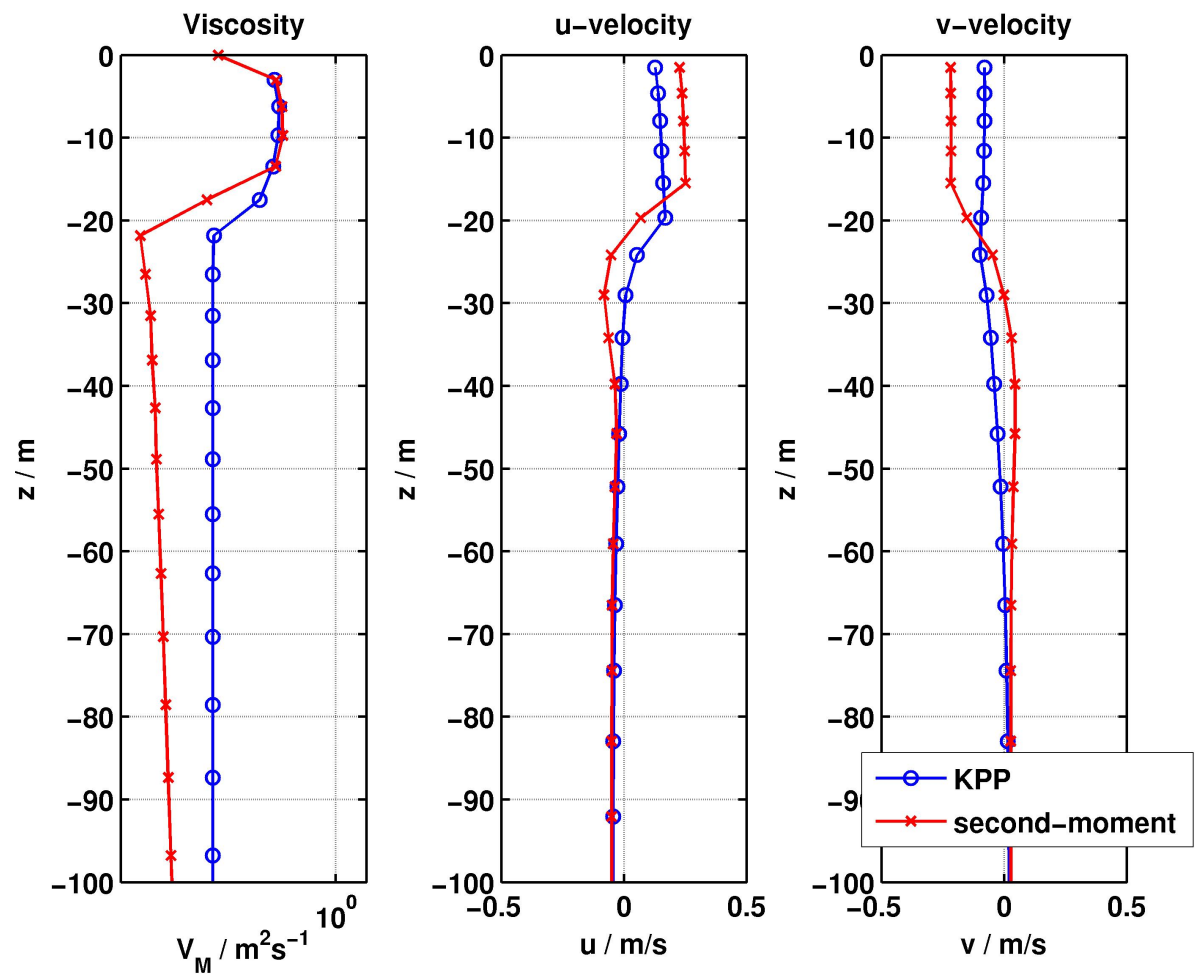

3, 1945-1976, 2006

\section{Validation and intercomparison of two vertical-mixing schemes}

V. Fernández et al.

Title Page

Abstract

Conclusions

Tables

14

4

Back

Fig. 12. Eddy viscosity and $u$ and $v$ velocity components from simulations in the LV station on 5 August 2004.

\section{Full Screen / Esc}

Printer-friendly Version

Interactive Discussion 

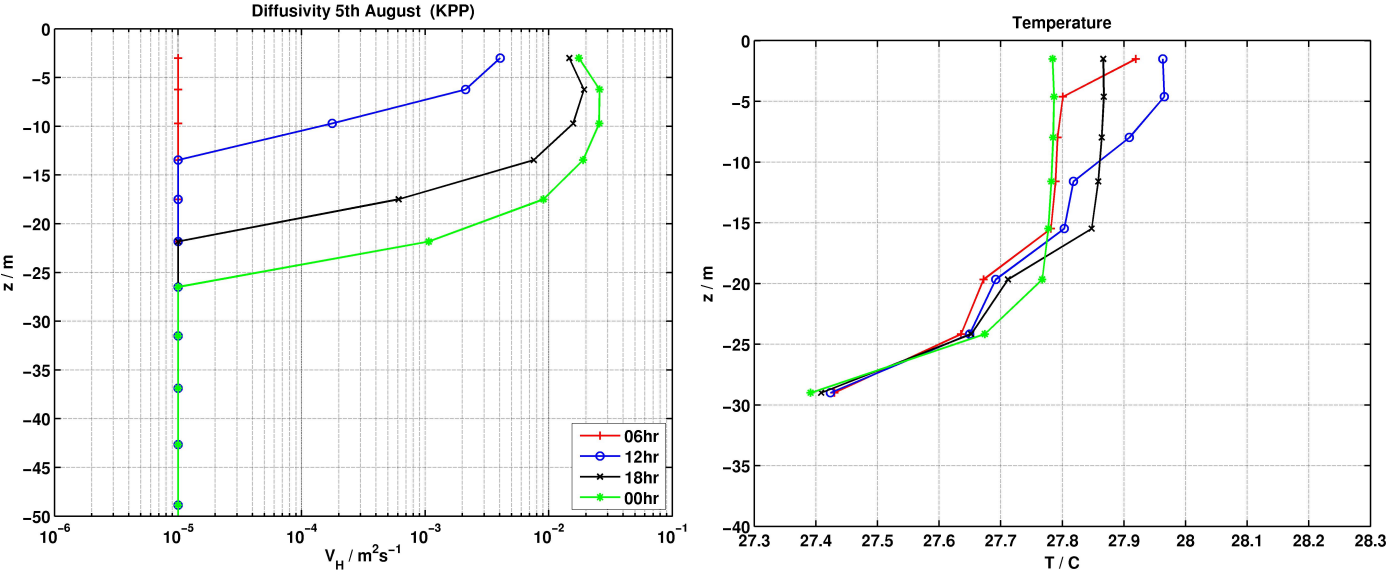

Fig. 13. Daily cycle of diffusivity (top) and temperature (down) on 5 August at the LV station for the KPP simulation. Each profile corresponds to a snapshot each $6 \mathrm{~h}$.

\section{Validation and intercomparison of two vertical-mixing schemes \\ V. Fernández et al.}

Title Page

Abstract

Introduction

Conclusions

References

Tables

Figures

14

- I

4

Back

Close

Full Screen / Esc

Printer-friendly Version

Interactive Discussion 
OSD

3, 1945-1976, 2006
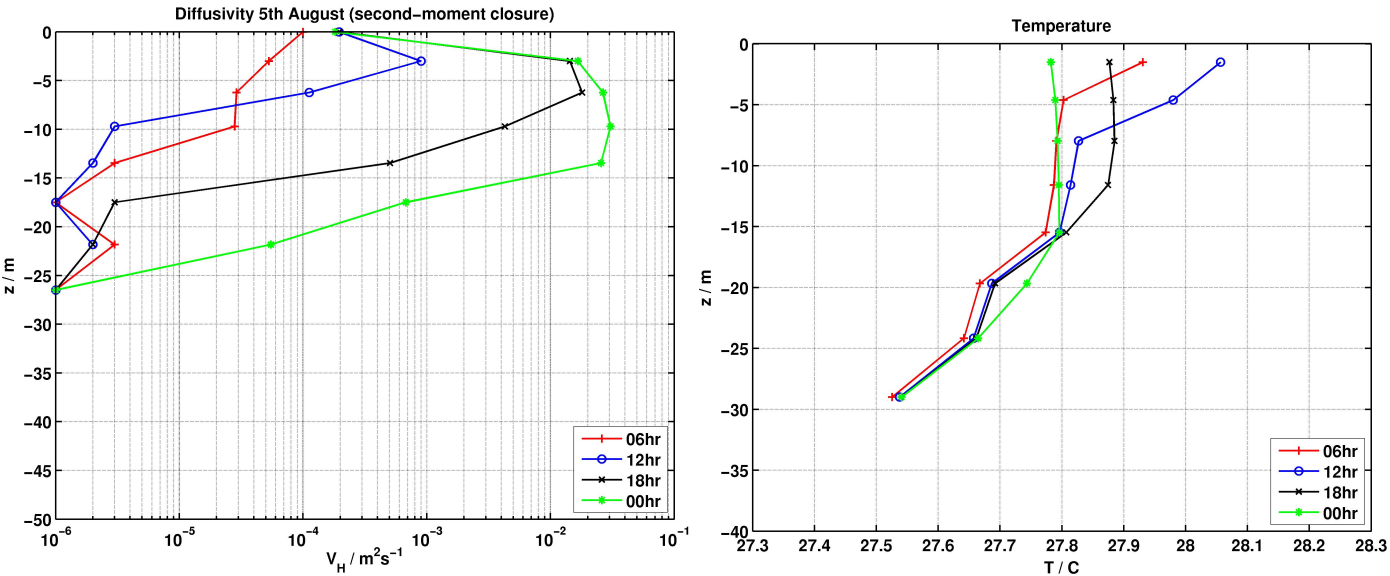

\section{Validation and intercomparison of two vertical-mixing schemes \\ V. Fernández et al.}

Title Page

Abstract

Introduction

Conclusions

References

Tables

Figures

Fig. 14. Same as Fig. 11 but for the second-moment simulation.

Back

Full Screen / Esc

Printer-friendly Version

Interactive Discussion 


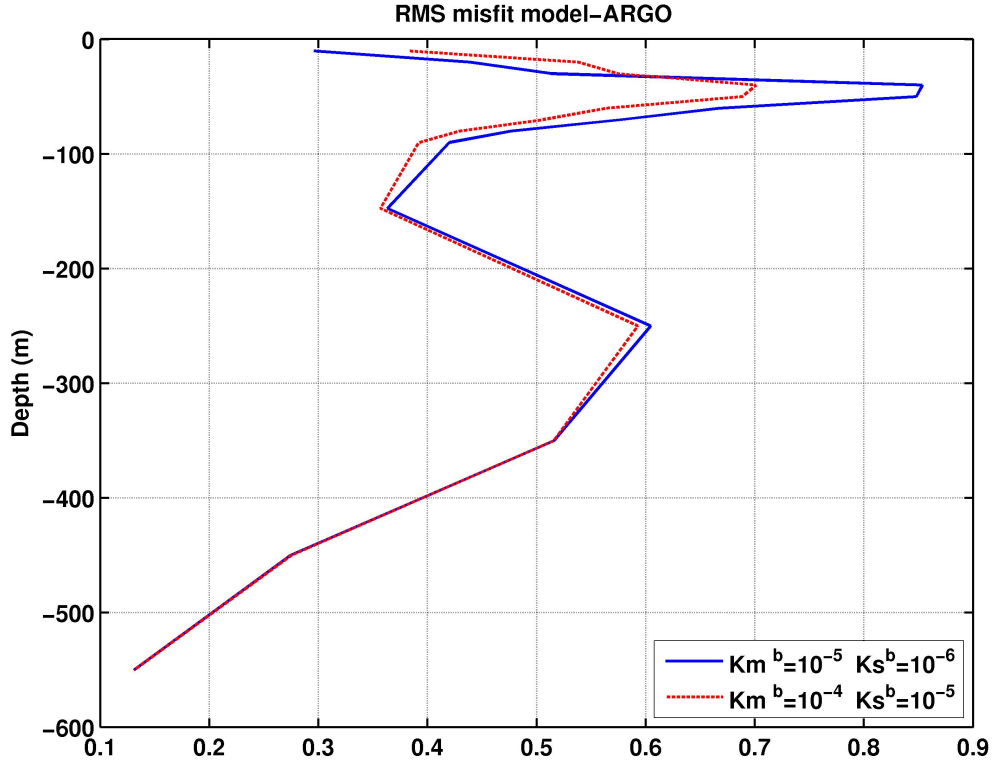

Fig. 15. RMS misfit in the LV station for different values of background interior mixing in the $\mathrm{KPP}$ simulations. $\mathrm{K}_{m}^{b}$ stands for viscosity and $\mathrm{K}_{s}^{b}$ for diffusivity (units in $\mathrm{m}^{2} / \mathrm{s}$ ).

\section{Validation and intercomparison of two vertical-mixing schemes}

V. Fernández et al.

Title Page

Abstract

Introduction

Conclusions

References

Tables

Figures

14

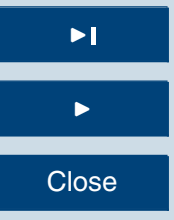

Back

Full Screen / Esc

Printer-friendly Version

Interactive Discussion 




Fig. 16. RMS misfit in the LV station for different values of minimum turbulent Kinetic energy $\mathrm{k}_{\min }$ in the second-moment closure model simulation. (Units are $\mathrm{J} / \mathrm{Kg}$ ).

\section{Validation and intercomparison of two vertical-mixing schemes}

V. Fernández et al.

Title Page

Abstract

Introduction

Conclusions

References

Tables

Figures

14 $\Delta$

4

Back

Close

Full Screen / Esc

Printer-friendly Version

Interactive Discussion 


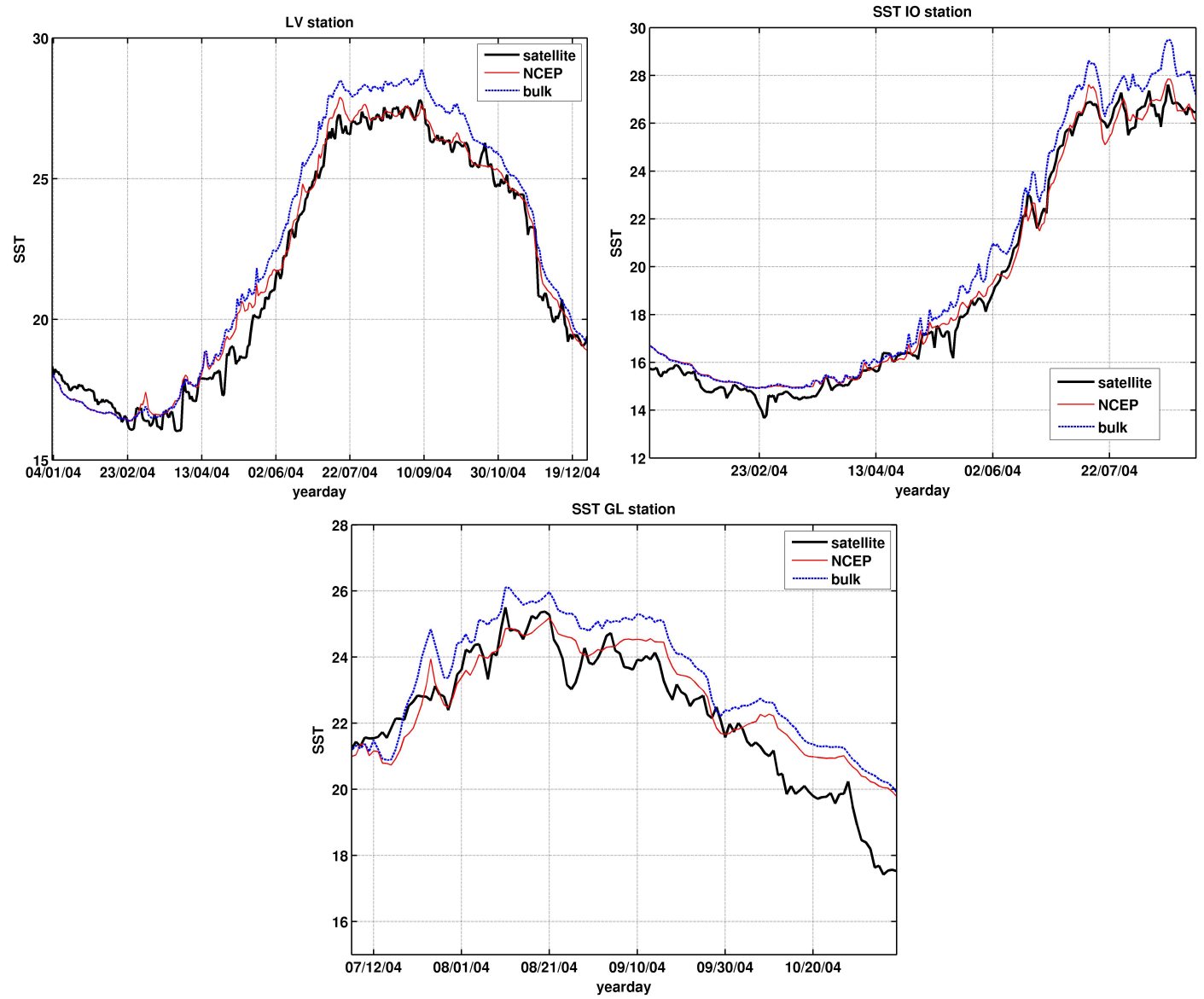

Fig. A1. Sea surface temperature (model and satellite) in the three stations. The model corresponds to the KPP simulations.
OSD

3, 1945-1976, 2006

\section{Validation and intercomparison of two vertical-mixing schemes}

V. Fernández et al.

Title Page

Abstract Introduction

Conclusions

References

Tables

Figures

14

Back

Close

Full Screen / Esc

Printer-friendly Version

Interactive Discussion 